\title{
Comparison between E-Learning Video and Smartphone Application for Information Technology Use in Nursing Education
}

\author{
Jung-Ha Park1)
}

\begin{abstract}
The present study was carried out to identify content on information-technology use in nursing education, develop it into eLearning video and smartphone applications, and apply them to nursing students to identify changes in their understanding and usage interest. Data were collected from April 1-15, 2019. The research participants were 64 first-year nursing students enrolled at a single nursing school in B City. The eLearning video and smartphone application were both applied to the experimental group for 2 weeks, while the control group used the eLearning video alone. The collected data were analyzed with the SPSS Win 24 Program, using descriptive statistics for general characteristics and a paired t-test and independent t-test for the research variables. The results showed that the differences in students' understanding of eLearning, virtual reality, social media, simulation, and application, before and after receiving the learning materials, were statistically significant in both the experimental and control groups. The usage interest in eLearning, virtual reality, social media, simulation, and applications showed statistically significant differences, before and after receiving the learning materials, in both the experimental and control groups. Based on the results of this study, further research is needed on the development and applicability of methods designed to teach nursing content to nursing students.
\end{abstract}

Keywords: eLearning, Video, Virtual Reality, Social, Media, Simulation, Application

\section{Introduction}

\subsection{The Need for this Study}

Now that the rapid development of cutting-edge new technologies and smart devices has made it possible to share information without time or place restrictions, interest has grown within the education sector in teaching methods that make use of the latest technology and reflect our changing times. In particular, many efforts to provide learner-centered education using information technology, such as ICT(Information and Communication Technology), the Internet, mobiles, simulation, and social networking, are underway.

In the nursing-education sector, there is particular interest in using information technology to provide eLearning, virtual reality, simulation, social learning, and other applications[1] to

Received (April 30, 2019), Review Result (1st: June 03, 2019, 2nd: August 14, 2019), Accepted (November 15, 2019)

1) (Assistant Professor) 47011 Dept. Nursing Science, Dongseo University, Jurye-ro, Sasang-gu, Busan, Korea email: suha2002@gdsu.dongseo.ac.kr 
provide learner-centered education, by adapting to changes in the educational environment.

eLearning is a learning system that enables anyone to access customized learning content that meets his or her individual needs anytime and anywhere, using information and communication technology[1]. Methods of injecting insulin[2], empirically-based clinical-nursing questions[3], intensive care nursing[4], and pediatric nursing[5] are among the topics covered through eLearning educational programs. Virtual reality makes it possible to use a computer to construct a simulated environment or situation that seems real[1]. Educational programs have been conducted on managing gastrointestinal bleeding[6], administering intravenous injections[7], and ways of using an intravenous-injection pump[8]. Social media enables bi-directional communication to be serviced online[1]; it has been studied as a way of providing a support structure for female college students[9]. Simulation is a technique that enables a subject to vividly experience virtual reality by using virtual reality to reproduce the structure of a real situation[1]. Related research has also been carried out about pediatric nursing[10], visit care[11], and integrated-nursing practices[12]. Application software is installed and used on a smartphone; its useful effects have been tested through research on drug-capacity learning[13] and drug-related nursing education[14]. However, the successful introduction of information technology to medical personnel, healthcare officials, clients, and caregivers depends on education, to provide users with a clear understanding of each type of information technology. Based on these research findings, educational information-technology content must be customized for each subject, developed, applied, and evaluated to determine its effects.

As previously discussed, an increasing number of educational approaches combine information with communication technology in the field of nursing education. This strategy maximizes the educational value of a course by integrating and harmonizing new technology with existing educational methods. Looking at the 'current status of wireless communication service subscribers' announced by the Ministry of Science, ICT and Future Planning in 2016, $83.2 \%$ of the total wireless telephone users are using a smart device[15]. With the popularization of wireless mobile devices, the usefulness of smartphones in nursing education[16] has attracted attention. Smartphones are frequently used for educational eLearning and educational applications.

The present study aimed to compare information-technology contents on eLearning, virtual reality, simulation, social learning, and applications; this content was disseminated through eLearning video and smartphone applications to test their educational impact.

\subsection{Purpose of this Research}


This research aimed to compare the educational methods on information-technology contents in nursing education, in the form of eLearning video and smartphone applications. Using these contents with nursing students would allow us to identify changes in their understanding and usage interest, providing basic data on the value of eLearning video and smartphone applications as approaches to teaching and learning.

\section{Research Methods}

\subsection{Research Design}

The present study has adopted a non-equivalent control group pre-test/post-test design to develop content on information-technology use in nursing education in eLearning video and smartphone applications, to compare the understanding and usage interest of nursing students].

\subsection{The Research Subjects and Data Collection}

The research subjects were first-year students in the nursing department of a single university in B City; the participants were enrolled in information-society and health courses; they understood the purpose of this research and gave their informed consent when agreeing to participate. Data were collected on April 1-15, 2019 and the intervention lasted 2 weeks. Of the 68 subjects who initially agreed to participate, 4 gave incomplete responses to surveys and their data were excluded, resulting in a total of 64 participants.

\subsection{Research Tools}

\subsubsection{Informatics Competency}

Informatics competency was measured using a scale developed by Staggers[17], translated by Kim[18], and revised and supplemented by Park[19] to suit nursing students. The informatics-competency tool consisted of 13 items across three areas of digital information management (6 items), perception of information (5 items), and information search (2 items). Items were ranked using a 5-point Likert scale, with responses ranging from 1 (strongly disagree) to 5 (strongly agree). Higher scores indicate a higher level of information competency. The reliability of this tool measured with Cronbach's a was .81 in Park's study[18] and .79 in this study. 


\subsubsection{Understanding}

Among various types of content on the use of information technology, we measured the participants' understanding of eLearning, virtual reality, social media, simulation, and applications using the visual analog scale (VAS). This measurement tool was first developed by Scott and Huskisson[20]. We used a 100mm ruler, with marks for every $5 \mathrm{~mm}$. The left end of the ruler represented the operational definition of "low," while the right end represented "high." Subjects used this tool to indicate their level of understanding of each item.

\subsubsection{Usage Interest}

Among various types of content on the use of information technology, we measured the participants' interest in using eLearning, virtual reality, social media, simulation, and applications, using the visual analog scale (VAS). The measurement was made using a $100 \mathrm{~mm}$ ruler with marks every 5mm, based on Scott and Huskisson[19]. The left end of the ruler represented the operational definition of "low," while the right end represented "high." Subjects used this tool to indicate their level of understanding of each item.

\subsection{Data-analysis Method}

The collected data were tested using a two-tailed test with a significance level of (a) of 0.05 , via the SPSS WIN 24 Program. The subjects' general characteristics were analyzed using descriptive statistics. The pre-test homogeneity of the participants' general characteristics and the research variables between the two groups were tested using an X2-test, Fisher's exact test, and a t-test. The understanding and usage interests of the two groups were analyzed using a paired $\mathrm{t}$-test and independent $\mathrm{t}$-test.

\section{Results}

The general characteristics of the research subjects and the results of homogeneity are shown in [Table 1]. Their pre-intervention information competency was $3.73 \pm 0.49$ for the experimental group and $3.60 \pm 0.44$ for the control group; the two groups were homogeneous $(t=1.16, p=.249)$. They were also homogeneous in their experience of using eLearning, virtual reality, social media, simulation, and applications. Among the contents of information-technology use, the experience of using eLearning was the most frequent in both the experimental group and the control group at $70 \%$ and $91.2 \%$, respectively. However, virtual reality had the highest intention 
to use in the experimental group and the control group at $73.3 \%$ and $88.2 \%$, respectively. Therefore, if the planning and production of educational content were based on virtual reality, one could expect that student usage will be high. In further research, it is recommended that nursing education on ethical or rare scenarios be carried out in virtual reality.

Their understanding of the information-technology usage content showed statistically significant differences before and after the experimental and control groups received their teaching materials. Overall, eLearning $(\mathrm{t}=-11.18, \mathrm{p}<.001 ; \mathrm{t}=-11.11, \mathrm{p}<.001)$, virtual reality $(\mathrm{t}=-13.59$, $\mathrm{p}<.001 ; \mathrm{t}=-10.02, \mathrm{p}<.001)$, social media $(\mathrm{t}=-7.21, \mathrm{p}<.001 ; \mathrm{t}=-7.24, \mathrm{p}<.001)$, simulation $(\mathrm{t}=-10.46$, $\mathrm{p}<.001 ; \mathrm{t}=-10.00, \mathrm{p}<.001)$, and application $(\mathrm{t}=-8.20, \mathrm{p}<.001 ; \mathrm{t}=-9.13, \mathrm{p}<.001)$ were statistically significant. The differences in the level of understanding of the two groups were statistically significant in relation to eLearning $(t=3.17, p=.003)$, virtual reality $(t=3.43, p=.001)$, social media $(\mathrm{t}=3.01, \mathrm{p}=.004)$, and applications $(\mathrm{t}=3.11, \mathrm{p}=.003)$ [Table 2]. Among the information-technology use contents eLearning, social media, and applications had high experience in use, but the level of understanding showed a big difference before and after education. In particular, applications were developed for drug dosage calculations[13] and high-risk drug education[14]; these have been applied to nursing students' education after their effectiveness was proven. Therefore, if students increase their level of understanding of the information-technology contents that they are currently using, the usage will be more effective.

The usage interest of the experimental and control groups showed statistically significant differences in relation to content involving information-technology use before and after both groups received their teaching materials. Specifically, eLearning $(t=-10.28, p<.001 ; t=-7.41$, $\mathrm{p}<.001)$, virtual reality $(\mathrm{t}=-10.22, \mathrm{p}<.001 ; \mathrm{t}=-9.00, \mathrm{p}<.001)$, social media $(\mathrm{t}=-6.82, \mathrm{p}<.001 ; \mathrm{t}=-7.11$, $\mathrm{p}<.001)$, simulation $(\mathrm{t}=-9.31, \mathrm{p}<.001 ; \mathrm{t}=-9.38, \mathrm{p}<.001)$, and application $(\mathrm{t}=-7.59, \mathrm{p}<.001 ; \mathrm{t}=-7.61$, $\mathrm{p}<.001)$ were statistically significant. The differences in the usage interests of the two groups were statistically significant in relation to eLearning $(t=2.73, p=.008)$, virtual reality $(t=2.84$, $\mathrm{p}=.006)$, social media $(\mathrm{t}=2.57, \mathrm{p}=.014)$, simulation $(\mathrm{t}=2.57, \mathrm{p}=.014)$, and applications $(\mathrm{t}=2.49$, $\mathrm{p}=.015)$ [Table 3].

[Table 2] Homogeneity Test of Study Variables at the Baseline ( $N=64)$

\begin{tabular}{|l|c|c|c|c|}
\hline \multicolumn{2}{|c|}{ Characteristics } & Exp. (n=30) & Cont. (n=34) & \multirow{2}{*}{$\mathrm{t} / \chi 2(\mathrm{p})$} \\
\cline { 2 - 4 } Gender & Male & $7(23.3)$ & $6(17.6)$ & \multirow{2}{*}{$(.757)$} \\
\cline { 2 - 4 } Age (year) & Female & $23(76.7)$ & $28(82.4)$ & \multirow{2}{*}{$-1.24(.222)$} \\
\hline \multirow{2}{*}{ Religion* } & & $18.13 \pm 0.35$ & $18.44 \pm 1.40$ & \multirow{2}{*}{$(.248)$} \\
\cline { 2 - 4 } & Catholic & $7(23.3)$ & $5(14.7)$ & \\
\hline
\end{tabular}


Comparison between eLearning video and Smartphone Application for Information Technology Use in Nursing Education

\begin{tabular}{|c|c|c|c|c|}
\hline & Buddhist & $4(13.3)$ & $3(8.8)$ & \\
\hline & None & $17(56.7)$ & $26(76.5)$ & \\
\hline o oarning ovnorionco* & Yes & $21(70)$ & $31(91.2)$ & $(052)$ \\
\hline eLearning experience & No & $9(30)$ & $3(8.8)$ & (.052) \\
\hline Virtual reality & Yes & $3(10)$ & $1(2.9)$ & $(333)$ \\
\hline experience* & No & $27(90)$ & $33(97.1)$ & (.030) \\
\hline Crail modia & Yes & $21(70)$ & $28(82.4)$ & $(276)$ \\
\hline social media experience & No & $9(30)$ & $6(17.6)$ & $(.3 / 6)$ \\
\hline Cimulation & Yes & $10(33.3)$ & $15(44.1)$ & $(446)$ \\
\hline Simuiation experience & No & $20(66.7)$ & $19(55.9)$ & (.446) \\
\hline & Yes & $24(80)$ & 31 (91.2) & \\
\hline Application experience & No & $6(20)$ & $3(8.8)$ & (.285) \\
\hline & eLearning & $1(3.3)$ & $1(2.9)$ & \\
\hline & Virtual reality & $22(73.3)$ & $30(88.2)$ & \\
\hline Intention to use* & Social & $1(3.3)$ & - & $(.512)$ \\
\hline & Simulation & $(16.7)$ & $2(5.9)$ & \\
\hline & Application & $1(3.3)$ & $1(2.9)$ & \\
\hline & $\begin{array}{c}\text { Digital information } \\
\text { management }\end{array}$ & $3.41 \pm 0.51$ & $3.04 \pm 0.50$ & $2.89(.005)$ \\
\hline Information & Perception of information & $3.83 \pm 0.42$ & $3.66 \pm 0.44$ & $1.50(.138)$ \\
\hline & Information search & $3.98 \pm 0.80$ & $4.10 \pm 0.74$ & $-6.21(.537)$ \\
\hline & Total & $3.73 \pm 0.49$ & $3.60 \pm 0.44$ & $1.16(.249)$ \\
\hline
\end{tabular}

Exp.=Experimental group; Cont.=Control group.

* Fisher's exact test

[Table 3] Differences in Variables between Groups

$(\mathrm{N}=64)$

\begin{tabular}{|c|c|c|c|c|c|c|c|}
\hline \multirow{2}{*}{\multicolumn{2}{|c|}{ Variable }} & PRe-test & POst-test & \multirow{2}{*}{$t$} & \multirow{2}{*}{$p$} & Difference & \multirow{2}{*}{$t(p)$} \\
\hline & & $\mathrm{M} \pm \mathrm{SD}$ & $\mathrm{M} \pm \mathrm{SD}$ & & & $\mathrm{M} \pm \mathrm{SD}$ & \\
\hline \multirow{2}{*}{ eLearning } & Exp. $(n=30)$ & $2.87 \pm 2.06$ & $7.47 \pm 1.41$ & -11.18 & $<.001$ & $4.60 \pm 2.25$ & \multirow{2}{*}{$3.17(.003)$} \\
\hline & Cont. $(n=34)$ & $3.85 \pm 1.69$ & $6.94 \pm 1.28$ & -11.11 & $<.001$ & $3.00 \pm 1.62$ & \\
\hline \multirow{2}{*}{$\begin{array}{l}\text { Virtual } \\
\text { reality }\end{array}$} & Exp. $(n=30)$ & $3.43 \pm 1.46$ & $7.83 \pm 1.29$ & -13.59 & $<.001$ & $4.40 \pm 1.77$ & \multirow{2}{*}{$3.43(.001)$} \\
\hline & Cont.(n=34) & $4.12 \pm 1.49$ & $7.03 \pm 1.17$ & -10.02 & $<.001$ & $2.91 \pm 1.69$ & \\
\hline \multirow{2}{*}{ Social media } & Exp. $\mathrm{n}=30$ ) & $4.43 \pm 2.34$ & $7.53 \pm 1.31$ & -7.21 & $<.001$ & $3.1 . \pm 2.35$ & \multirow{2}{*}{$3.01(.004)$} \\
\hline & Cont. $(\mathrm{n}=34)$ & $5.56 \pm 1.80$ & $7.18 \pm 1.24$ & -7.24 & $<.001$ & $1.61 \pm 1.30$ & \\
\hline \multirow{2}{*}{ Simulation } & Exp. $(n=30)$ & $3.73 \pm 1.91$ & $7.53 \pm 1.48$ & -10.46 & $<.001$ & $3.80 \pm 1.99$ & \multirow{2}{*}{$1.64(.106)$} \\
\hline & Cont. $(\mathrm{n}=34)$ & $3.97 \pm 1.82$ & $7.00 \pm 1.41$ & -10.00 & $<.001$ & $3.03 \pm 1.77$ & \\
\hline \multirow{2}{*}{ Application } & Exp. $(\mathrm{n}=30)$ & $4.43 \pm 2.43$ & $7.67 \pm 1.94$ & -8.20 & $<.001$ & $3.23 \pm 2.16$ & \multirow{2}{*}{$3.11(.003)$} \\
\hline & Cont. $(n=34)$ & $5.24 \pm 1.76$ & $7.09 \pm 1.14$ & -9.13 & $<.001$ & $1.85 \pm 1.18$ & \\
\hline
\end{tabular}

Exp.=Experimental group; Cont.=Control group.

[Table 4] Differences in Variables between Groups

$(\mathrm{N}=64)$

\begin{tabular}{|c|c|c|c|c|c|c|c|}
\hline \multirow{2}{*}{\multicolumn{2}{|c|}{ Variable }} & PRe-test & POst-test & \multirow{2}{*}{$t$} & \multirow{2}{*}{$p$} & Difference & \multirow{2}{*}{$t(p)$} \\
\hline & & $\mathrm{M} \pm \mathrm{SD}$ & $\mathrm{M} \pm \mathrm{SD}$ & & & $\mathrm{M} \pm \mathrm{SD}$ & \\
\hline \multirow{2}{*}{ eLearning } & Exp. $(n=30)$ & $3.03 \pm 2.01$ & $7.37 \pm 1.38$ & -10.28 & $<.001$ & $4.33 \pm 2.33$ & \multirow{2}{*}{$2.73(.008)$} \\
\hline & Cont. $(n=34)$ & $3.68 \pm 1.84$ & $6.47 \pm 1.75$ & -7.41 & $<.001$ & $2.79 \pm 2.20$ & \\
\hline
\end{tabular}


http://dx.doi.org/10.21742/apjcri.2019.12.05

\begin{tabular}{|c|c|c|c|c|c|c|c|}
\hline \multirow{2}{*}{ Virtual reality } & Exp. $(n=30)$ & $4.00 \pm 2.26$ & $8.07 \pm 1.34$ & -10.22 & $<.001$ & $4.07 \pm 2.18$ & \multirow{2}{*}{$2.84(.006)$} \\
\hline & Cont. $(\mathrm{n}=34)$ & $4.50 \pm 1.88$ & $7.18 \pm 1.09$ & -9.00 & $<.001$ & $2.68 \pm 1.74$ & \\
\hline \multirow{2}{*}{ Social media } & Exp. $(n=30)$ & $4.97 \pm 2.66$ & $7.80 \pm 1.47$ & -6.82 & $<.001$ & $2.83 \pm 2.28$ & \multirow{2}{*}{$2.57(.014)$} \\
\hline & Cont.(n=34) & $5.76 \pm 1.76$ & $7.38 \pm 1.30$ & -7.11 & $<.001$ & $1.61 \pm 1.33$ & \\
\hline \multirow{2}{*}{ Simulation } & Exp. $(n=30)$ & $4.00 \pm 2.46$ & $7.73 \pm 1.44$ & -9.31 & $<.001$ & $2.83 \pm 2.28$ & \multirow{2}{*}{$2.57(.014)$} \\
\hline & Cont. $(n=34)$ & $4.62 \pm 1.88$ & $7.03 \pm 1.55$ & -9.38 & $<.001$ & $1.61 \pm 1.33$ & \\
\hline \multirow{2}{*}{ Application } & Exp. $(n=30)$ & $4.93 \pm 2.46$ & $8.00 \pm 1.34$ & -7.59 & $<.001$ & $3.07 \pm 2.21$ & \multirow{2}{*}{$2.49(.015)$} \\
\hline & Cont.(n=34) & $5.18 \pm 2.12$ & $7.09 \pm 1.38$ & -7.61 & $<.001$ & $1.91 \pm 1.46$ & \\
\hline
\end{tabular}

Exp.=Experimental group; Cont.=Control group.

\section{Conclusion}

In this study, an eLearning video and an application were developed to provide nursing students with educational content on information-technology use. Over 2-weeks, the control group received an eLearning video, while the experimental group received an eLearning video and the application. The content consisted of 5 items related to eLearning, virtual reality, social media, simulation, and applications.

The eLearning video was produced in the form of 10-15 minute long videos; eLearning related to corresponding subjects taught at the Center for Teaching and Learning was also provided, enabling the students to take classes. An application was developed using the eLearning video and loaded into the app store and Androids market so that all smartphone users could download the application and use it with no time or space restraints.

The result showed that the differences in students' understanding and usage interest between eLearning videos and application. There is a need for an evaluation of learner utilization and effectiveness through developing and implementing smart device-based information-technology content that attracts high user interest in this research.

\section{Acknowledgements}

This work was supported by Dongseo University's 2019 "Dongseo Cluster Project" Research Fund (DSU-20190011).

\section{References}

[1] H. A. Park, I. S. Cho, J. A. Kim, J. E. Kim, H. S. Kim, E. H. Min, M. H. Park, K. A. Seomoon, E. K. Yun, N. J. Lee, S. M. Lee, E. J. Lee and M. N. Choi, Nursing Informatics, Hyunmoon Publishers, (2017) 
[2] Y. M. Kim, M. S. You, Y. H. Cho, S. H. Park, S. N. Nam and M. Y. Kim, EEffects of a New-Nurse Education Program Utilizing E-learning and Instructor Demonstration on Insulin Injection Practices, Journal of Korean Clinical Nursing Research, (2011), Vol.17, No.3, pp.411-420.

[3] M. R. Jeong and M. H. Park, Development and Effects of E-Learning Program for Clinical Questioning in Evidence-Based Practice Using Case-Based Animation for Nurses, Korean Journal of Adult Nursing, (2018), Vol.30, No.6, pp.643-655, DOI: 10.7475/kjan.2018.30.6.643

[4] K. S. Kim, J. A. Kim and J. W. Ahn, Development and Implementation of a Self-directed Critical Care Nursing e-Learning Program, Perspectives in Nursing Science, (2012), Vol.9, No.1, pp.51-60.

[5] S. Y. Kim, Analysis on the types of eLearning process in nursing students, Seoul National University, Doctoral Dissertation, (2007)

[6] S. J. Park, Development and evaluation of a virtual simulation program on nursing care for patients with acute upper gastrointestinal bleeding, Kyung Hee University, Master's Thesis, (2018)

[7] W. Tsai, C. Fung, S. Tsai, M. Jeng and J. Doong, The assessment of stability and reliability of a virtual reality-based intravenous injection simulator, Computers, Informatics, and Nursing, (2008), Vol.26, No.4, pp.221-226, DOI: 10.1097/01.NCN.0000304804.46369.5a

[8] M. Luctkar-Flude, C. Pulling and M. Larocque, Ending infusion confusion: Does a virtual intravenous pump educational module enhance transfer of skills to practice?, Clinical Simulation in Nursing, (2010), Vol.6, No.3, pp.118-119, DOI: https://doi.org/10.1016/j.ecns.2010.03.047

[9] S. J. Nam, Effects of social media based support system on premenstrual syndrome and physical activity among female university students with premenstrual syndrome, Ewha University, Master's Thesis, (2017)

[10] H. S. Shin, K. K. Shim, Nursing students' experiences on pediatric nursing simulation practice, Journal of East-West Nursing Research, (2010), Vol.16, No.2, pp.147-155, UCI: G704-SER000012890.2010.16.2.012

[11] Y. J. Kim, J. H. Park, Effects of Visiting Nursing Simulation-Based Training for Community Nursing, Journal of Korea Society for Simulation in Nursing, (2016), Vol.4, No.2, pp.21-35.

[12] E. M. Kwak, Effects of simulation-based integrated nursing practice on nursing students, Asia-Pacific Journal of Multimedia Services Convergent with Art, Humanities, and Sociology, (2017), Vol.7, No.10, pp.445-455, DOI: 10.35873/ajmahs.2017.7.10.041

[13] M. S. Kim and J. H. Park, Development of a Drug Dosage Calculation Learning Smartphone Application, Journal of Korea Academia-Industrial cooperation Society, (2013), Vol.14, No.5, pp.2251-2261, DOI: $10.5762 /$ KAIS.2013.14.5.2251

[14] J. H. Park and M. H. Kim, Development and Evaluation of Medication Nursing Education Program based on Smartphone, Asia-pacific Journal of Multimedia Services Convergent with Art, Humanities, and Sociology, (2019), Vol.9, No.3, pp.449-457, DOI: 10.35873/ajmahs.2019.9.3.042

[15] https://www.sedaily.com/NewsView/1KXS0EMB7I, Jun 29 (2016)

[16] J. C. Phillippi, T. H. Wyatt, Smartphones in Nursing Education, Computers, Informatics, Nursing, (2011), Vol.29, No.8, pp.449-454, DOI: 10.1097/NCN.0b013e3181fc411f 
[17] N. Staggers, C. A. Gassert and C. Curran, A Delphi study to determine informatics competencies for nurses at four levels of practice, Nursing Research, (2002), Vol.51, No.6, pp.383-390, DOI: 10.1097/00006199-200211000-00006

[18] M. S. Kim, Validity and Reliability of Informatics Competencies for Nurses Among Korean Nurses, Korean Journal of Adult Nursing, (2008), Vol.20, No.3, pp.470-480, UCI: G704-000678.2008.20.3.001

[19] J. E. Park, The relationship between information literacy, nursing process competency and evidence-based practice competency of nursing students, Kyung Hee University, Master's Thesis, (2018)

[20] J. Scott and E. C. Huskisson, Vertical or horizontal visual analogue scales, Annals of the Rheumatic Diseases, (1979), Vol.38, No.6, p.560, DOI: 10.1136/ard.38.6.560 